\title{
Engineering Students' Algebra Difficulties: An Experiment with Computer-Aided Diagnostic Assessment
}

\author{
Agostinho Iaqchan Ryokiti Homa (1) \\ ${ }^{a}$ Universidade Luterana do Brasil, Programa de Pós-Graduação em Ensino de Ciências e Matemática, Canoas, RS, Brasil \\ Received for publication on 1 Mar. 2020. Accepted after review on 7 Sep. 2020 \\ Designated editor: Claudia Lisete Oliveira Groenwald
}

\begin{abstract}
Context: Engineering students have difficulties in solving problems involving Differential Calculus, and this is attributed to the epistemological difficulties of Calculus and the lack of mastery of algebraic manipulations. Objectives: The study investigates the problems with the basic mathematics of Engineering students through the analysis of error, making this error an observable object so that, in the self-management of knowledge, students take the necessary actions, if they wish, to develop the mathematical skills necessary to exercise the profession of Engineering. Design: For the study, qualitative research was carried out to investigate the difficulties in potentiation, radication, factorization, simplification, distributive property of multiplication in relation to addition, the order of operations, algebraic fractions, polynomials, and solution of polynomial and non-polynomial equations of a group of students from Engineering courses. Setting and participants: Students regularly enrolled in Engineering courses at Universidade Luterana do Brasil. Data collection and analysis: Data were extracted from the database of the computer-aided diagnostic assessment system (ADAC) after students performed their self-assessment. Results: In general, all students in the group had some difficulty with at least one of the evaluated contents. Even considering that the error can happen due to distraction, the number of students who answered incorrectly to two or more items by evaluated content was high, suggesting that the group has greater mathematical difficulties related to Algebra, in particular: simplifications, potentiation, operations with fractions, with roots and solving nonpolynomial equations. Conclusion: For graduates of engineering courses, the use of mathematics to solve engineering problems is one of the skills to be developed during their training. From the results of the research carried out, the mathematical difficulties of most students in the group with some of the evaluated concepts were evident.
\end{abstract}

Keywords: Mathematics Education, Higher education, Computer-Aided Diagnostic Assessment.

Corresponting author: Agostinho laqchan Ryokiti Homa. Email: iaqchan@hotmail.com 


\section{As dificuldades em álgebra dos estudantes de engenharia: um experimento com avaliação diagnóstica auxiliada por computador}

\section{RESUMO}

Contexto: Parte dos estudantes de engenharia têm dificuldades na resolução de problemas que envolvem o Cálculo Diferencial e atribui-se isto às dificuldades epistemológicas do Cálculo, a falta de domínio das manipulações algébricas. Objetivos: $\mathrm{O}$ estudo investiga os problemas com a matemática básica dos estudantes de Engenharias através da análise do erro, tornando esse erro um objeto observável para que, na autogestão do conhecimento, os alunos tomem as ações necessárias, se assim o quiserem, para desenvolverem as competências matemáticas necessárias ao exercício da profissão de Engenheiro. Delineamento: Para o estudo realizou-se uma pesquisa qualitativa para investigar as dificuldades em potenciação, radiciação, fatoração, simplificação, propriedade distributiva da multiplicação em relação a adição, ordem das operações, frações algébricas, polinômios e solução de equações polinomiais e não polinomiais de um grupo de estudantes dos cursos de Engenharias. Cenário e participantes: Alunos regularmente matriculados nos cursos de Engenharias da Universidade Luterana do Brasil. Coleta e análise dos dados: Os dados foram extraídos do banco de dados do sistema de avaliação diagnóstica auxiliada por computador (ADAC) após os estudantes realizarem a sua auto avaliação. Resultados: No geral, todos os alunos do grupo apresentaram alguma dificuldade com pelo menos um dos conteúdos avaliados. Mesmo considerando que o erro pode acontecer por distração, foi elevada a quantidade de alunos que responderam incorretamente a dois ou mais itens por conteúdo avaliado, sugerindo que o grupo apresenta maiores dificuldades matemáticas relativas a Álgebra, em específico: simplificações, operações com frações, potenciação, radiciação e resolução de equações não polinomiais. Conclusão: Para os graduandos dos cursos de engenharias, o uso da matemática para a resolução de problemas de engenharia é uma das competências a serem desenvolvidas durante sua formação. Pelos resultados da pesquisa realizada, ficaram evidentes as dificuldades matemáticas da maioria dos alunos do grupo com alguns dos conceitos avaliados.

Palavras-chave: Educação Matemática, Ensino Superior, Avaliação Diagnóstica Auxiliada por Computador.

\section{INTRODUÇÃO}

This article is an excerpt from the doctoral thesis with the theme of diagnostic assessment of mathematics, developed in the Postgraduate Program in Teaching of Science and Mathematics (PPGECIM) Programa de Pós Graduação em Ensino de Ciências e Matemática. It presents the results of the application of a Computer-Aided Diagnostic Assessment (ADAC) with students of Relative Engineering as mathematical difficulties in algebra, calculated are considered as disciplines of Differential and Integral Calculus.

The objective of this article is to present the difficulties concerning algebraic knowledge, necessary to solve problems involving the concept of Derivatives, so that students, participants in the experiment, know their difficulties and, with a focus on selfmanagement of knowledge, take actions to the development of the skills necessary for the exercise of their future profession.

The theoretical framework is organized with the themes related to the mathematical skills of engineers and error analysis that supported the developed ADAC. 


\section{MATHEMATICAL SKILLS OF ENGINEERS}

The concept of competence is presented, from a work perspective, as something desirable and, from a pedagogical perspective, as necessary for the integral formation of the individual. Competences have their source in the professional area, which, in a training process for the exercise of work activity, was defined as the skills that make the individual able to perform a specific task in a given profession. This definition was broadened when there was a change in training for the qualification of the individual, so that, in addition to the knowledge, skills, and attitudes necessary for the exercise of the profession, planning, flexibility, and autonomy were included as characteristics to be developed, extending to a broader professional base, moving from specialization to non-specialization (Bunk, 1994). Within the professional scope, Le Boterf(2001) defines competence as a combination of resources, such as knowledge, know-how, attitudes, and environmental resources, such as information and relationships that are mobilized to perform an action.

Bunk (1994) distinguishes formal competence, an assignment conferred or granted, from real competence, which are the skills acquired for the adequate performance of actions in certain situations. Indeed, for the exercise of the profession, real skills are the ones that matter, and, within the pedagogical focus, it is understood that the development of these skills requires integrated training processes for the composition, in the individual, of the set of desired professional skills.

Capabilities are composed of knowledge, skills, and attitudes, to carry out activities, but including aspects of organization and planning, to solve professional problems autonomously and collaborate in their professional environment (Bunk, 1994).

For the development of high-level competencies, according to Flores (2007), it is necessary to have general competencies that support and support learning, including basic skills, or elementary knowledge, such as reading, writing, mathematical literacy, communication, and the attitude of continuous learning.

For the engineering professional, among the general skills that support the development of high-level skills, mathematical skills stand out, such as logical and mathematical reasoning, mathematical language, including reading and interpreting graphs, modelling and problem solving, and the ability to communicate, from natural language to mathematical representations and vice versa.

\section{THE SKILLS DEVELOPED IN THE ENGINEERING COURSE}

The anthropological view that considers man to be an incomplete being understands that his situation leads him, therefore, to be a transforming agent of nature and the idea of transforming the environment is the main activity of the engineer. Therefore, the engineering objective of manipulating and controlling nature involves the need to identify, relate and mathematize, making explicit the need for the conceptual structure on functions, 
together with the understanding of the phenomena's value and variation characteristics. Thus, the mathematical knowledge presented in the Calculus disciplines is essential for the modelling and mathematization of the problem situation.

In the National Curricular Guidelines (DCN) for Undergraduate Engineering Courses in Brazil and in the definitions of international accreditation programs for engineering courses, such as EUR-ACE (EURopean ACcredited Engineer) and ABET (Accreditation Board for Engineering and Technology ) mathematical skills are observed directly and indirectly in their definitions and criteria.

The EUR-ACE Standards and Guidelines for Accreditation of Engineering Programmes (2015) lay down that the learning process should enable Bachelor Degree graduates to demonstrate knowledge and understanding of the mathematics and other basic sciences underlying their engineering specialization, at a level necessary to achieve the other program outcomes. For ABET (2019), the student must have the ability to identify, formulate, and solve complex engineering problems by applying principles of engineering, science, and mathematics. In Brazil, the DCN for Undergraduate Engineering Courses (2019) establishes that graduates from the Engineering undergraduate course must be able to model the phenomena, physical and chemical systems, using mathematical, statistical, computational, and simulation tools, as well as predict the results of the systems through the models. So that engineering involves the purposeful application of mathematical and natural sciences and a body of engineering knowledge, technology, and techniques.

In this way, being competent mathematically influences success as a professional, so mathematical knowledge is relevant to the development of the skills required for graduates of these courses. Some mathematical concepts are considered general knowledge, such as mathematical reading, use of mathematical symbology, algebraic manipulation, elementary knowledge of geometry. however, others are considered complex, such as the use of mathematics in solving professional problems and in modelling problems.

One of the goals of engineering courses is to develop students' mathematical skills and competencies, but during this process, some mistakes or errors do not allow the correct execution of the activities proposed during the training.

\section{ERROR ANALYSIS}

Errors appear in the productions due to misunderstandings about fundamental aspects of mathematics, due to the incorrect use of data, the use of the wrong model, the use of systematic wrong procedures, incurring algebraic manipulations, for not taking into account the restrictions established in the situation-problem, and for other reasons according to Cury $(2003,2007)$, Pochulu (2009) e Rico (1998). For each of these reasons, the error, or misunderstanding, appears as evidence associated with a cause, so that the analysis of the error allows to identify the reason, what are the difficulties of the students in carrying out certain mathematical activities. 
It is the concern of the teacher and the student to understand and solve the causes of the difficulties that lead to the inadequate execution of the proposed activities. The student, focusing on his training, within the paradigm of self-management of knowledge; and the teacher, with a more general view, to evaluate his pedagogical practice and the didactics employed, analyzing the group of students that do not reach the proposed objectives.

A characteristic of mathematical problems is that a student's answer can be classified as right or wrong and, even when it is possible to subdivide into partial solutions, the answers to them are still of the right or wrong type (Rico, 1998). Focusing on incorrect answers, the error is identified as evidence of the lack or deficiency of knowledge, method or process, which leads the student, in the face of a particular problem situation, to answer incorrectly, which is the basic premise for the development of this research.

It is understood that errors are part of the students' production during the learning of mathematics and can contribute to the teaching-learning process (BORASI, 1996; (Borasi, 1996; Cury, 2003; Rezende, 2003; Rico, 1998) therefore, the student's error, expresses the incompleteness of their knowledge, allowing them to interfere with learning what is missing.

Therefore, the error is an essential part of the learning process, since the construction of new knowledge is based on the previous ones. In the course of their training, the formalization and mistaken systematization of knowledge can lead the student to make mistakes, due to inadequate inferences, based on this previous knowledge or due to the lack of understanding of the new knowledge, caused by the pedagogical action of the teacher or by intrinsic difficulties of the discipline (Cabral \& Baldino, 2008; Rico, 1998).

According to Rico (1998), the fallibility of an individual or collective knowledge is the ability to consider concepts and procedures that are inadequately developed as valid, including contradictory ideas, interpretations, and false justifications. Therefore, errors do not appear by chance; they emerge based on a consistent conceptual framework and based on a priori knowledge, associated with the logical thinking and the individual's intuition on the subject, which uses an empiricist logic.

For most researchers, the error is not an accidental action, but something that arises from strategies and personal rules used in solving problems and based on their particular experiences, interpretations, and initial mathematical knowledge (Borasi, 1996; Cury, 2003; Rezende, 2003; Rico, 1998). Thus, most errors are extremely persistent, as they reflect the student's knowledge of a concept. However, some errors occur due to chance or distraction, but these are less persistent, as they do not reflect the student's real or inadequate knowledge.

Important results are found in the regularity of errors or consistent patterns of errors. Individually, there is a pattern when the student shows the same error when performing similar activities or mathematical problems; at the collective level, the pattern is revealed when different people are making the same mistakes at certain stages of learning development. 
Brousseau, Werner, and Davis (1986) call attention to some characteristics of errors in students' productions: errors are often the result of some systematic procedure that contains a failure, being used frequently and consistently; students often have misconceptions about fundamental aspects of mathematics; the student's observation shows that he frequently uses flawed procedures and has misconceptions, which are not recognized by the teacher; students often invent their methods and even ignore the method presented by the teacher.

The information processing method assumes that mathematical problems can be broken down into various processing components and, as these difficulties are internal, it is necessary to use indirect methods of observation. Among them is the analysis of the subjects' errors and their mathematical productions. (Rico, 1998).

Despite the classification difficulties, the categorizations provide essential and important information for research in mathematical learning, as well as assist the teacher in his practice, by understanding and predicting specific persistent errors of the collective, allowing the planning of actions aimed at reducing the problems of learning associated topics.

To have access to information about the student's knowledge on a topic and its associated difficulties, the student must express it, in written, spoken, or other forms of expression, so that an analysis can be performed and value of judgment is assigned about that information. The research used a computational assessment tool, seeking to access knowledge and identify the difficulties associated with errors during the assessment.

\section{RESEARCH METHODOLOGY}

The investigation aimed to identify the concepts, previous or those associated with the epistemology of Calculus, that students of engineering courses do not master, and that makes it difficult to solve problems involving Derivatives through one of a computeraided diagnosis system. To achieve the goal, it was developed as a self-assessment tool so that the student can identify his difficulties, providing information about his knowledge about a topic making the error an observable object, allowing the student to interact and overcome it.

The system called ADAC (Computer-Aided Diagnostic Assessment), composed of two assessments, one on the knowledge of algebra and the other on problem-solving involving the concepts of Derivatives, was used in an experiment carried out with a group of 30 students, called from A1 to A30, respectively, enrolled in the Differential and Integral Calculus disciplines of the engineering courses at the Universidade Luterana do Brasil.

This article presents the results related to the assessment called Mathematics. The items of this assessment aimed to identify the existence of difficulties related to algebra, developed in Basic Education, because the researches carried out by Cury (2003), Feltes 
(2007), Pochulu (2009), and Ferreira (2005) point out algebraic difficulties as the most relevant cause of mathematical errors in Higher Education.

The Mathematics assessment items were organized with the sequence: algebraic expressions, application of the distributive property of multiplication over addition and subtraction, algebraic simplifications, operations with algebraic fractions, non-polynomial equations (exponential, trigonometric, logarithmic), radication, and potentiation.

Being a computational system, the questions are of the false/true type, composed of a statement that presents an equality or an inequality, to verify the existence of difficulty to the object of evaluation. The textual part of the question is similar for all items of the Mathematical assessment and reinforces the need to be answered to self-assess, recommending not to select random answers. The text of the statement of the items is: Determine whether equality (inequality) is true or false. Respond based on your knowledge. Do not choose an answer at random; remember that this assessment is to identify your difficulties.

Each evaluated topic contains three pairs of items (A, B, C), composed of a false statement (AF) and a true statement (AV), for the same evaluation object, totalling six items, which are presented according to errors and respondent's correct answers. The topic assessment is organized according to Figure 3 and starts with a false statement (AF). If the topic is answered incorrectly, or if to obtain one of the alternatives I'm not sure or I don't know, ADAC forwards to another false statement (AF) and, responding correctly, ADAC forwards to a true statement (AV) of the same type, confirming the knowledge related to the subject.

\section{Figure 3}

Diagram of the items related to a topic of Mathematical assessment (Homa, 2010, p. 96)

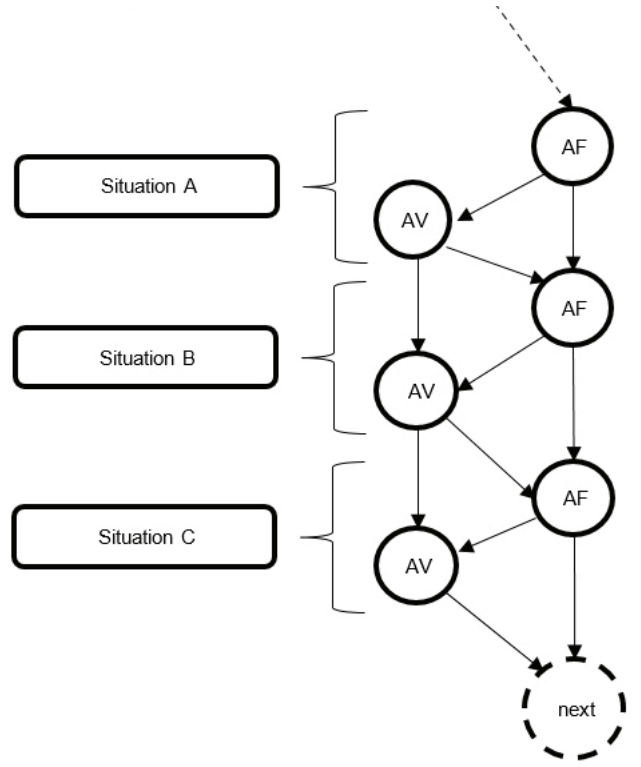


This organization allows the presentation of three to six items, depending on the respondents' mistakes and successes to the evaluated topic. The mathematical diagnostic assessment with the concepts of Algebra has 42 items that are presented according to the student's performance during the assessment and defined by the chain rules described.

\section{DATA ANALYSIS}

ADAC was implemented as a WEB system and, being a computational assessment, students were able to carry out activities outside the institution. Everyone was informed about the research objectives and instructed how they should respond to the assessment, and the character of the self-assessment as an instrument for the self-management of knowledge and evidencing the need for reliable answers to their knowledge.

About the participants we have that, of the thirty students, seventeen are 25 years old or more, which suggests the existence of a period, between High School and Higher Education, in which the student was outside any educational institution since all participants are the second or third semester of their courses. Students under 25 years old total thirteen, with only two under 20 years old.

Regarding the difficulty of the items in the Mathematical assessment, half of the students considered it as difficult or very difficult, attributing their errors and difficulties to poor learning in elementary and high school, the lack of study, and errors due to distraction. When asked whether they should know how to resolve the issues, eighteen students fully agreed that they should know how to resolve the items, one student disagreed with the others did not give an opinion.

For a global analysis of the mathematical assessment and the group of participants, Table 1 shows the number of students who answered incorrectly, that is, they selected a wrong option or stated categorically that they did not know with the option I don't know. The columns are organized with the quantities for at least one item, two or more items, and three wrong items. Taking as a reference the students who answered incorrectly to three items about the same content, only two contents are below $30 \%$, the order of operations, and the distributive property of the multiplication on the addition, which are the items that the students had fewer difficulties.

Table 1 shows that for all concepts, a considerable proportion of students made at least one item wrong, but it must be considered that some errors may be made by mistake or distraction. Therefore, the information pertinent to the student, and the focus of his attention are the contents that he has mistaken two or more times. 
Number of students with wrong answers by mathematical content

\begin{tabular}{|c|c|c|c|c|c|c|}
\hline \multirow{2}{*}{$\begin{array}{c}\text { Number of students with } \\
\text { Algebraic expressions (potentiation) }\end{array}$} & \multicolumn{2}{|c|}{$\begin{array}{c}\text { at least } 1 \\
\text { wrong answers }\end{array}$} & \multicolumn{2}{|c|}{$\begin{array}{c}\text { at least } 2 \\
\text { wrong answers }\end{array}$} & \multicolumn{2}{|c|}{$\begin{array}{l}3 \text { wrong } \\
\text { answers }\end{array}$} \\
\hline & 27 & $90 \%$ & 22 & $73 \%$ & 18 & $60 \%$ \\
\hline Algebraic expressions (order of operations) & 22 & $73 \%$ & 10 & $33 \%$ & 6 & $20 \%$ \\
\hline $\begin{array}{l}\text { Algebraic expressions (distributive property } \\
\text { of multiplication over addition) }\end{array}$ & 23 & $77 \%$ & 12 & $40 \%$ & 8 & $27 \%$ \\
\hline $\begin{array}{l}\text { Algebraic expressions (simplification rational } \\
\text { expressions) }\end{array}$ & 29 & $97 \%$ & 25 & $83 \%$ & 14 & $47 \%$ \\
\hline Algebraic expressions (algebraic fractions) & 23 & $77 \%$ & 19 & $63 \%$ & 15 & $50 \%$ \\
\hline Solution of non-polynomial equations & 30 & $100 \%$ & 28 & $93 \%$ & 25 & $83 \%$ \\
\hline Algebraic expressions (operation with roots) & 27 & $90 \%$ & 22 & $73 \%$ & 22 & $73 \%$ \\
\hline
\end{tabular}

Analyzing the concepts adopted, Table 2 presents a set of 6 items with the same algebraic expressions involving an order of basic operations. This set of items was presented to thirty students, with 22 of them missing at least one item and ten responding incorrectly to two or more items.

The M1/M2 sequence has a low number of errors, but, even involving only addition and multiplication, four students answered incorrectly (A7, A14, A36, A37) and, analyzing their performance, it appears that A14, A36, and A37 responded incorrectly to two more items in the set. Of the 26 students referred to M2, two students, A1 and A24, answered incorrectly, with A1 missing only this item, which suggests an error due to distraction, and A24 missing two other items.

Table 2

Number of incorrect answers - Order of operations

\begin{tabular}{|c|c|c|c|c|c|c|}
\hline & Item statement & 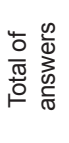 & $\begin{array}{l}0 \\
\frac{0}{5} \\
\frac{0}{3}\end{array}$ & 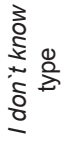 & 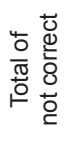 & 융ำ \\
\hline M1 & $3+(2-b) \cdot a=5 a-a b$ & 30 & 3 & 1 & 4 & 13 \\
\hline M2 & $(5 x+3 y)+(4 x+2 y) \cdot 2=13 x+7 y$ & 26 & 2 & 0 & 2 & 8 \\
\hline M3 & $2(3 a+b)^{2}=(6 a+2 b)^{2}$ & 6 & 3 & 0 & 3 & 50 \\
\hline M4 & $3(y+x)^{2}=(3 y+3 x)(y+x)$ & 27 & 13 & 2 & 15 & 56 \\
\hline M5 & $12-5 \operatorname{sen}(2 x)=7 \operatorname{sen}(2 x)$ & 18 & 3 & 3 & 6 & 33 \\
\hline M6 & $a+b .2-b=a+b$ & 24 & 6 & 0 & 6 & 25 \\
\hline
\end{tabular}


The percentage of errors for M3 and M4 rises to $50 \%$ and suggests difficulties in the order of operations when it involves multiplication and potentiation. By the presentation logic, item M3 was answered by six students, three of whom considered it correct to apply the distributive property of multiplication about addition, before potentiation, showing a mistaken generalization learned in middle school and high school students Médio (Feltes, 2007), that continues in Higher Education. Item M4, with the highest percentage of errors, was answered incorrectly by thirteen students, suggesting difficulties in identifying the power as the product of two terms, in which it is possible to apply the associative and distributive properties of multiplication over addition.

Item M5 has a trigonometric expression and was answered incorrectly by six students, three stating that equality was true and three stating that they did not know if it was correct. The error and the doubts are supposed to be because the students first add up the numbers, ignoring the precedence of multiplication over addition.

Item M6 was identified as an invalid equality by six students because the habit of writing the product of polynomials without parentheses (Cury, 2003) makes students identify equality as incorrect since they interpret it as a product of two binomials.

For being simple algebraic expressions, the incorrect answers to the items show difficulties in elementary algebraic manipulations, which are reflected in the more complex algebraic operations, involving several operations, like the other items of the Mathematical assessment.

The items to assess difficulties in the application of the distributive property of multiplication over addition bring different situations, among which the misplaced generalization of the product of two binomials (M7, M11) and multiplication operations on the right and left.

Table 3 presents the response numbers for the set of items for Algebraic Expressions (distributive property of multiplication over addition). Item M12 stood out without a wrong answer, being like M7 and M11, with $37 \%$ and $46 \%$ of wrong answers, respectively. Analyzing the set of items, 24 students responded to items M7 and M12, with six students (A1, A3, A13, A16, A21, A38) missing M7 and hitting M12. This suggests a mistaken generalization when the terms are the same in both binomials, as is the case with M7.

For M12, as the terms of the binomial are different, students correctly operate. Therefore, these students know and know how to apply the multiplicative distributive property over addition, but they show that they have their own rule for the product of binomials with equal terms. This can also be seen from the number of errors in M11.

Item M8, with $58 \%$ of wrong answers, shows that, even though knowing that equality in M7 is wrong, more than half of the students directed to M8 do not identify that it presents correct equality, not identifying algebraic simplification. 


\begin{tabular}{|c|c|c|c|c|c|c|}
\hline & Item statement & 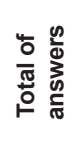 & $\begin{array}{l}\frac{0}{0} \\
\frac{5}{3} \\
\frac{0}{3}\end{array}$ & 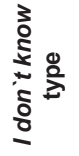 & 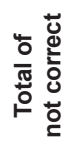 & ○ \\
\hline M7 & $(x-y)(-x+y)=-x^{2}-y^{2}$ & 30 & 11 & 0 & 11 & 37 \\
\hline M8 & $\left(3 x y^{2}-x y\right) \frac{x}{y}=\left(3 x^{2} y-x^{2}\right)$ & 19 & 5 & 6 & 11 & 58 \\
\hline M9 & $2\left(\frac{x}{4}-\frac{y}{9}\right) 3=\frac{x}{2}-\frac{y}{3}$ & 22 & 2 & 7 & 9 & 41 \\
\hline M10 & $x^{2}+2 x y-x-2 y=-x(1-x)+2 y(x-1)$ & 21 & 2 & 2 & 4 & 19 \\
\hline M11 & $(2 x+y)(x+3 y)=2 x^{2}+3 y^{2}$ & 13 & 5 & 1 & 6 & 46 \\
\hline M12 & $(w+y)(z-k)=z w-k w+z y-k y$ & 24 & 0 & 0 & 0 & 0 \\
\hline
\end{tabular}

By chaining logic, item M9 is presented to those who miss M7 or M8. It was identified that $30 \%$ of the students declared that they did not know if it was correct or not. Item M10 is the second item with the fewest errors with two wrong answers and two I don't know.

To assess the difficulties in simplification rational expressions, items were constructed to verify whether students establish equivalence relations between the given fraction and the result obtained by simplification. The results in Table 4 show that part of the group has difficulties regarding the content, with the results of item M16 being strong evidence for this statement, with $86 \%$ of wrong answers.

\section{Table 4}

Number of incorrect answers - Simplification rational expressions

\begin{tabular}{|c|c|c|c|c|c|c|}
\hline & Item statement & 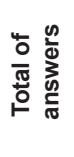 & $\begin{array}{l}\frac{0}{0} \\
\frac{5}{3}\end{array}$ & 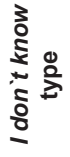 & 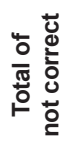 & ㅇํำ \\
\hline M13 & $\frac{6 x^{2}+2 y^{2}}{6}=x^{2}+2 y^{2}$ & 30 & 8 & 1 & 9 & 30 \\
\hline M14 & $\frac{8 y x^{2}-4 y^{3} x}{2 x y}=4 x-2 y^{2}$ & 21 & 6 & 2 & 8 & 38 \\
\hline
\end{tabular}




\begin{tabular}{|c|c|c|c|c|c|c|}
\hline & Item statement & 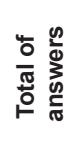 & $\begin{array}{l}0 \\
\text { के } \\
\frac{0}{3} \\
3\end{array}$ & 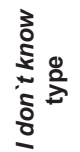 & 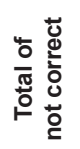 & ㅇํำ \\
\hline M15 & $\frac{4(x-y)}{k+(x-y)}=\frac{4}{k}$ & 17 & 5 & 3 & 8 & 47 \\
\hline M16 & $\frac{4 x-2 x y}{(2-y) 4}=\frac{x}{2}$ & 22 & 14 & 5 & 19 & 86 \\
\hline M17 & $\frac{3 x+2 y}{x+2}=3+y$ & 27 & 8 & 7 & 15 & 56 \\
\hline M18 & $\frac{8 x^{2}-y x}{x^{2}}=8-\frac{y}{x}$ & 15 & 6 & 1 & 7 & 47 \\
\hline
\end{tabular}

Concerning errors in simplification of algebraic fractions, Notari (2002) identifies the simplification of just one of the terms of a sum of the numerator or denominator, as errors made by high school and higher education students. This situation is presented in M13 and M15, and part of the group considers this simplification to be valid, with the largest number of incorrect answers to the answers I don't know. Item M17 presents a double incorrect simplification with 56\% incorrect answers, with the number of answers I don't know close to the incorrect ones, showing that in this situation there are doubts in this type of operation.

The true statements M14 and M18 have, respectively, 38\% and 47\% of wrong answers and reduced number of answers of the type I don't know, that is, students are sure that the simplifications are wrong, not identifying the items as true statements.

Item M16, with $86 \%$ incorrect answers, 14 wrong answers, and five I don't know answers, suggests difficulties in identifying the common factors for the simplification of the algebraic fraction.

To assess the difficulties in operations with algebraic fractions, items M19 to M24 explore situations with the operations of adding, dividing fractions and solving first degree equations. Considering the group of participants and the content evaluated, it appears that nineteen students erred two or more items in the set, indicating the lack of mastery in operations with algebraic fractions by $63 \%$ of the group.

From the results in Table 5, M19 (PA) was answered incorrectly by thirteen students, who are directed to M21 (PA), with 93\% of wrong answers, and then to M23 (PA), with $94 \%$ of answers wrong. Through the database, it was possible to identify twelve students who answered incorrectly to this sequence of $\mathrm{AF}$ items, indicating that these students have great difficulties in performing operations with algebraic fractions. 
Analyzing the sequence of the three true questions, M20, M22, and M24, it was identified that seven students got the three items right. Table 5 shows that items M20, M22, and M24 had 12\%, 25\%, and 46\% of wrong answers, respectively, with a percentage increase as items, increased in difficulty and, consequently, a gradual targeting to AF items.

\begin{tabular}{|c|c|c|c|c|c|c|}
\hline & Item statement & 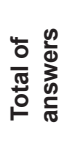 & $\frac{0}{3}$ & 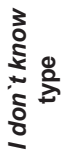 & 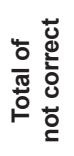 & ㅇํำ \\
\hline M19 & $\frac{5}{y}+\frac{2}{x}=\frac{7}{x+y}$ & 30 & 7 & 6 & 13 & 43 \\
\hline M20 & $\frac{x}{2}+\frac{y}{4}=\frac{2 x+y}{4}$ & 17 & 2 & 0 & 2 & 12 \\
\hline M21 & $3 x=\frac{y}{6} \Rightarrow x=\frac{\frac{y}{6}}{3} \Rightarrow x=\frac{y}{2}$ & 15 & 6 & 8 & 14 & 93 \\
\hline M22 & $\frac{2}{3} x=\frac{y}{6} \Rightarrow x=\frac{\frac{y}{6}}{\frac{2}{3}} \Rightarrow x=\frac{y}{4}$ & 16 & 4 & 0 & 4 & 25 \\
\hline M23 & $\frac{\frac{x}{4}-1}{\frac{3}{4}-\frac{x}{2}}=\left(\frac{x}{4}-1\right) \cdot\left(\frac{4}{3}-\frac{2}{x}\right)$ & 18 & 10 & 7 & 17 & 94 \\
\hline M24 & $\frac{\frac{4 x}{3}-x}{2 x-\frac{5 x}{3}}=1$ para $x \neq 0$ & 13 & 4 & 2 & 6 & 46 \\
\hline
\end{tabular}

This set of items corroborates the mathematical difficulties related to operations with algebraic fractions, by presenting situations to which the students did not respond correctly, incurring the errors identified by Notari (2002).

Non-polynomial equations (exponential, trigonometric, and logarithmic) were assessment by items M25 to M30 and are evaluated in Table 6 . It should be noted that the group had the worst performance in these items, with all participants answering incorrectly to at least one of the items and 25 missing the three items.

For the pair of items M25 and M26, which request the solution of an exponential equation, 26 students answered incorrectly to one of the two items. The pair of items M27 and M28 had, respectively, $81 \%$ and $89 \%$ of wrong answers, showing the difficulties related to solving trigonometric equations. Items M29 and M20 had $66 \%$ and $73 \%$ of wrong answers. 
Other relevant information about the students' knowledge regarding the solution of non-polynomial equations can be inferred from the relationship between the answers of the type I don't know and the wrong answers. Except for item M28, the other items have twice or more answers I don't know, compared to the number of wrong answers.

Table 6

Number of incorrect answers - Non-polynomial equations

\begin{tabular}{|c|c|c|c|c|c|c|}
\hline & Item statement & 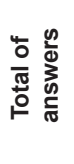 & $\begin{array}{l}\frac{0}{0} \\
\frac{1}{3}\end{array}$ & $\begin{array}{l}3 \\
\vdots \\
\vdots \\
\vdots \\
\vdots \\
\vdots \\
0\end{array}$ & 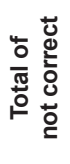 & ஃㅇํำ \\
\hline M25 & $3^{x}-2=7 \Rightarrow x=\sqrt[3]{5}$ & 30 & 6 & 11 & 17 & 57 \\
\hline M26 & $5^{x}=4 \Rightarrow x=\frac{\log 4}{\log 5}$ & 13 & 3 & 6 & 9 & 69 \\
\hline M27 & $\operatorname{sen} 2 y=3 \Rightarrow y=\operatorname{arcsen} \frac{3}{2}$ & 26 & 7 & 14 & 21 & 81 \\
\hline M28 & $\cos (3-y)=5 \Rightarrow y=3-\arccos 5$ & 9 & 5 & 3 & 8 & 89 \\
\hline M29 & $\ln (y+2)=5 \Rightarrow \ln y=3$ & 29 & 5 & 14 & 19 & 66 \\
\hline M30 & $5=\ln (4 y) \Rightarrow y=\frac{e^{5}}{4}$ & 11 & 2 & 6 & 8 & 73 \\
\hline
\end{tabular}

The option I don't know cannot be considered a distractor, as it does not bring a situation that a student with little knowledge can consider to be true. When the student says that he/she does not know, he/she shows that he/she does not know the object of assessment, stating that he/she has no idea what is right, wrong, or what to do.

This group of items reaffirms the importance of options of the type I don't know in diagnostic assessment, as they allow the student to show interested parties their knowledge about the object of assessment.

Analyzing the group of participants according to Table 7, low performance is also observed, with 27 students ( $73 \%$ ) incorrectly answering at least one of the items. Through the database, it was identified that nine students answered incorrectly to the sequence of items M31, M33, and M35, indicating difficulties of this group of students.

The data in Table 7 show that eighteen students answered incorrectly to item M31, so the students mistakenly understand that the root of the sum is the sum of the roots. The chaining logic presented the item M32 for the nine students who answered M31 correctly, but six of these nine students did not know that M32 presents true equality showing a partial knowledge of these students about root simplification. 
The inequality in M33 was answered by 27 students with sixteen incorrect answers and four answers I don't know, representing 74\% of incorrect answers. Item M34 was answered by ten students, with only one wrong answer, and suggests the understanding that the root of the product is equal to the product of the roots, but the understanding of a mechanized operation produces a misleading generalization for the sum, as in M31.

Table 7

Number of incorrect answers - Operation with roots

\begin{tabular}{|c|c|c|c|c|c|c|}
\hline & Item statement & 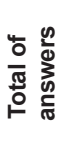 & $\begin{array}{l}0 \\
\frac{0}{0} \\
\frac{0}{3}\end{array}$ & 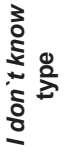 & 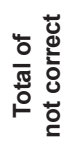 & $\circ \frac{\text { g }}{2}$ \\
\hline M31 & $\sqrt{x^{2}+y^{2}}=x+y$ & 30 & 18 & 3 & 21 & 70 \\
\hline M32 & $x \sqrt{x y}=\sqrt{x^{3} y}$ & 9 & 5 & 1 & 6 & 67 \\
\hline M33 & $\sqrt{9(x+y)^{2}} \neq 3 x+3 y$ & 27 & 16 & 4 & 20 & 74 \\
\hline M34 & $\sqrt{121 x^{4} y^{2}}=11 x^{2} y$ & 10 & 1 & 0 & 1 & 10 \\
\hline M35 & $\sqrt{\frac{16 x^{2}}{2}} \neq 2 x \sqrt{2}$ & 21 & 9 & 6 & 15 & 71 \\
\hline M36 & $\sqrt{\frac{x^{3}}{4 y^{2}}}=\frac{x}{2 y} \sqrt{x}$ & 15 & 0 & 7 & 7 & 47 \\
\hline
\end{tabular}

Item M35, with nine wrong answers and six answers I don't know, totalled $71 \%$ of incorrect answers. All students who missed the M33 inequality were directed to M35, evidencing problems of this group with properties of square-root. Item M36 had 47\% incorrect answers, but with the interesting fact that they are type, I don 't know. Considering that the students who scored M34 and M35 are the ones who answered M36, it is not clear why the seven answers do not know, maybe related to difficulties with the rationalization applied in the right term.

The group of participants performed poorly on items with mathematical expressions involving potentiation. It was identified that 27 students $(73 \%)$ answered incorrectly to at least one item, and 22 students missed two or more items.

The number of wrong answers observed for item M37, in Table 8, shows that twenty students $(83 \%)$ answered incorrectly to the item, which was developed to verify whether students are confused when considering that the numerical and literal parts are elevated to the same power, even if they are without parentheses. This fact is proven by the results, because $83 \%$ applied the rule by changing the term raised to the power, from the denominator to the numerator, and changing the sign of the power, but ignoring that 
it is applied only to the x. It appears that the five students who scored M37 also answered M38 correctly, so it is possible to say that these students understand this situation.

Item M39, which was presented to the 25 students who also answered M37 incorrectly, was answered incorrectly by sixteen students who considered it correct that the sum of powers of the same base is equal to the product of powers of the same base, making it clear the use of distorted theorems or definitions as categorized by Hadar et al. (1987).

Table 8

Number of incorrect answers - Potentiation

\begin{tabular}{|c|c|c|c|c|c|c|}
\hline & Item statement & 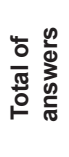 & $\begin{array}{l}\frac{0}{0} \\
\frac{0}{3} \\
\frac{1}{3}\end{array}$ & 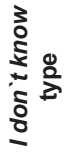 & 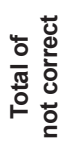 & ㅇํำ \\
\hline M37 & $\frac{1}{3 x^{2}}=3 x^{-2}$ & 30 & 20 & 5 & 25 & 83 \\
\hline M38 & $4 x^{-\frac{5}{3}}=\frac{4}{\sqrt[3]{x^{5}}}$ & 5 & 0 & 0 & 0 & 0 \\
\hline M39 & $x^{2}+x^{3}=x^{5}$ & 25 & 16 & 1 & 17 & 68 \\
\hline M40 & $4 a^{4} 5 a^{3}=20 a^{7}$ & 13 & 2 & 0 & 2 & 15 \\
\hline M41 & $(x-y)^{2}=x^{2}+y^{2}$ & 19 & 8 & 1 & 9 & 47 \\
\hline M42 & $(x-1)^{3}=-(1-x)^{3}$ & 21 & 10 & 2 & 12 & 57 \\
\hline
\end{tabular}

Item M40, showing the correct operation of powers, was answered correctly by eleven of thirteen students and only two (A4 and A39) answered that the operations were wrong. Analyzing the data of A4, it was found that it missed two simplifications of algebraic fractions and two potentiation operations, including M40. Student A39, on the other hand, missed the three operations with the distributive property, two simplifications, three algebraic fractions, three operations with square roots, and three potentiation operations. The data suggest that A4 presents some difficulty with simplification and enhancement and A34 has difficulties in operations and algebraic manipulations in general.

The mistaken generalization that the power of the sum is the sum of the powers leads to the identification of M41 as correct (FELTES, 2007), with eight out of nineteen students missing the item. Item M42, with 57\% of wrong answers, presents an unusual situation that requires more elaborate manipulation and, perhaps, for this reason, the one not identified as being correct. 
Crossing some answers, it was identified that the two students who answered M3 correctly, identifying the distributive property on power as wrong, stated that M42 is false, perhaps because they understand this as a similar situation. This shows the lack of knowledge about the power properties, as well as algebraic operations that justify M42 as correct.

In general, all students in the group had some difficulty with at least one of the evaluated contents. An interesting fact could be observed by analyzing the performance of student A26, who got all the algebraic fractions correct, answered that he did not know how to solve all non-polynomial equations, and answered all operations incorrectly with roots.

\section{FINAL CONSIDERATIONS}

The Mathematical assessment was solved by 30 participants and produced 844 responses to the items with 428 correct answers, equivalent to $51 \%$ of the answers, and 416 incorrect answers, corresponding to a total of $49 \%$, distributed between wrong answers and answers of the type I don't know. The percentage of wrong answers shows, in the participating group, the existence of difficulties related to the contents of Algebra of this evaluation, which is studied in the final years of Middle School and High School.

Since the answers are not correct, the focus of the analysis, and considering the universe of 416 incorrect answers of the Mathematical evaluation, and the answers of the type I don't know represented $35.5 \%$ of these, being an important source of information about the students' knowledge, because these expressed, directly and explicitly, their lack of knowledge about the object of evaluation, attributing a greater degree of precision to the inference about the difficulties of the respondents, as it is understood that when stating that they do not know, the student assumes their difficulty about the object of evaluation.

As it is a self-assessment evaluation, the inclusion of the options I don't know and I am not sure, allows the student to clearly express his difficulty with the assessment object presented in the item. It is understood that questions of the true or false type with only these two options make the student choose at random, not allowing to identify his difficulty, being necessary to present other items for a better inference. These items were used as answers because the students understood that they were not being subjected to a selection or qualification exam, as is the case with tests in subjects where the choice of a random answer can improve the score.

Even considering that the error can happen due to distraction, the number of students who answered incorrectly to two or more items by evaluated content was high, suggesting that the group has greater mathematical difficulties related to Algebra, in particular: simplifications, potentiation, operations with fractions, with roots and solving non-polynomial equations. 
For graduates of engineering courses, the use of mathematics to solve engineering problems is one of the skills to be developed during their training. From the results of the research carried out, the mathematical difficulties of most students in the group with some of the evaluated concepts were evident.

\section{AUTHORS' CONTRIBUTIONS STATEMENTS}

AIRH conceived the idea and adapted the methodology by developing the activities and the ADAC System to collect the data, as well as carrying out the analyzes, as part of his $\mathrm{PhD}$ research.

\section{DATA AVAILABILITY STATEMENT}

The data were obtained from the students' activity reports when performing the mathematical diagnostic assessment is available at ADAC at http://ppgecim.ulbra.br/ adac/painel/, and will be made available by the corresponding author, AIRH, upon reasonable request.

\section{REFERÊNCIAS}

ABET. (2019). Criteria for Accrediting Engineering Programs.

Borasi, R. (1996). Reconceiving Mathematics Instruction: A Focus on Errors. Ablex. Brousseau, G., Werner, T., \& Davis, R. B. (1986). Observing student at work. In: B. Christiansen, A. G. Howson, \& M.Otte (Eds.), Perspective on Mathematics Education. Reidel.

Bunk, G. (1994). La transmisión de las competencias en la formación y perfeccionamiento profesionales de la RFA. Revista Europea de Formación Profesional, 1, 8-14.

Cabral, T. C. B., \& Baldino, R. R. (2008, July 27). Cálculo Infinitesimal para um curso de Engenharia. Revista de Ensino de Engenharia. https://doi.org/10.5335/ree.v25i1.216 Cury, H. N. (2003). Análise de erros em cálculo diferencial e integral: resultados de investigações em cursos de engenharia. In: Anais do XXXI Congresso Brasileiro de Ensino de Engenharia. http://www.abenge.org.br/cobenges-anteriores/2003/2003--xxxicobenge-rio-de-janeiro-rj

Cury, H. N. (2007). Análise de Erros: o que podemos aprender com as respostas dos alunos. Autêntica.

European Network for Engineering Accreditation. (2015). EUR-ACE Framework Standards and Guidelines. Mental Health Practice, (31).

Feltes, R. Z. (2007). Análise de erros em Potenciação e radiciação: um estudo com alunos de Ensino Fundamental e Médio. (p. 1-136). http://tardis.pucrs.br/dspace/ bitstream/10923/3108/1/000388459-Texto+Completo-0.pdf 
Ferreira, D. H. L., \& Brumatti, R. N. M. (2005). Dificuldades em matemática em um curso de engenharia elétrica. Horizontes, 27(1), 51-60.

Flores, J. G. (2007). La evaluación de competencias laborales. Educación XX1, 10(0), 83-106. https://doi.org/10.5944/educxx1.1.10.297

Hadar, N. M., Zaslavsky, O., \& Inbar, S. (1987). An Empirical Classification Model for Errors in High School Mathematics. Journal for Research in Mathematics Education, 18(1), 3-14.

Homa, A. I. R. (2010). Universidade luterana do brasil. Universidade Luterana do Brasil. Le Boterf, G. (2001). Ingeniería de las competencias. Colección formación y desarrollo (Vol. 4).

Notari, A. M. (2002). Simplificação de frações aritméticas e algébricas : Um diagnóstico comparativo dos procedimentos. Pontifícia Universidade Católica - São Paulo.

Pochulu, M. (2009). Análisis y categorización de errores en el aprendizaje de la matemática en alumnos que ingresan a la universidad. Revista Iberoamericana de Educación, 1-15. Rezende, W. M. (2003). O ensino de Cálculo: dificuldades de natureza epistemológica. Universidade de São Paulo. http://www.teses.usp.br/teses/disponiveis/48/48134/tde27022014-121106/publico/WANDERLEY_REZENDE.pdf

Rico, L. (1998). Errores en el aprendizaje de las matemáticas. In J. Kilpatrick, P. Gómez, \& L. Rico (Eds.), Educación Matemática. Iberoamérica. 